\title{
Effect of Molten Pool Shape on Tensile Shear Strength of Dissimilar Materials Laser Spot Joint between Plastic and Metal
}

\author{
Yu KURAKAKE ${ }^{* 1}$, Yusof FARAZILA ${ }^{* 2}$, Yukio MIYASHITA ${ }^{* 3}$, Yuichi OTSUKA ${ }^{* 4}$ and Yoshiharu MUTOH $^{* 4}$ \\ ${ }^{*}$ Graduate student, Department of Mechanical Engineering, Nagaoka University of Technology, \\ 1603-1 Kamitomioka, Nagaoka, Niigata 940-2188, Japan \\ E-mail:miyayuki@mech.nagaokaut.ac.jp \\ ${ }^{* 2}$ Department of Engineering Design and Manufacture, University of Malaya, Malaysia \\ ${ }^{* 3}$ Department of Mechanical Engineering, Nagaoka University of Technology \\ ${ }^{* 4}$ Department of System Safety, Nagaoka University of Technology
}

\begin{abstract}
Dissimilar materials laser spot joining between polyethylene terephthalate (PET) and aluminum alloy (A5052) was studied by using pulse YAG laser. The results showed that it was possible to make a joint in a wide range of heat input. Molten pool was formed at the interface of A5052 and depth of molten pool increased with increase in heat input. Tensile shear test was carried out to evaluate strength of the joints. The result showed that tensile shear strength increased with increase in the heat input when the molten pool filled with molten or softened PET. On the other hand, instability of joining state inside the molten pool might induce variation in the strength. FEM analysis was carried out to investigate effect of molten pool shape on the strength. The result showed that molten pool radius did not significantly affect tensile shear strength. In contrast, the joint strength increased with increase in the molten pool depth as observed in result of the experiment. It is proposed that taking into account the mechanical effect such as molten pool shape is an important approach to improve the joining strength under tensile shear loading.

DOI:10.2961/jlmn.2013.02.0008
\end{abstract}

Keywords: Dissimilar materials joint, Pulse YAG laser, PET, A5052, FEM analysis, Loading mode

\section{Introduction}

The demand for dissimilar materials joining has been increased to create a new structure and a new function of an instrument or a component in many industrial fields. However, it is difficult to make a dissimilar materials joint with high reliability on its strength. Typically, mechanical joining or adhesive bonding is used for dissimilar materials joining between a plastic and a metal. However, those joining methods need an additional part or material only for joining purpose and result in a limitation of reduction in size, weight and cost of a component. Therefore, direct joining as an alternative joining method for dissimilar materials is strongly required.

Recently, laser direct joining technique between a plastic and a metal has been investigated. Katayama et al. successfully developed a new laser direct joining process for lapped plates of a plastic and a metal, which was called LAMP joining [1]. On the other hand, in the case of laser spot joining for a micro scale component, improvement of joining strength is unavoidable because of the limitation in size of the joining area. The authors studied direct laser spot joining between polyethylene terephthalate (PET) and different metallic materials [2]. It was possible to make a joint between PET and an aluminum alloy (A5052), a stainless steel (SUS304) or a commercially pure cupper (C1220) as shown in Fig. 1. According to the cross sectional observation of the joints, molten pool was formed in PET/A5052 and PET/SUS304 joints. Moreover, an increase in heat input increased the molten pool depth and the joining strength. In addition, the molten pool depth in PET/A5052 joint significantly changed with change in welding conditions compared to PET/SUS304 joint.

In this study, spot joining of dissimilar materials between PET and A5052 was carried out by using pulse YAG laser. The joining experiment and the FEM analysis were conducted to investigate the effect of the molten pool shape on the joining strength under tensile shear load. The way to improve the joining strength is also discussed based on the results of the experiment as well as the analysis.

\section{Experimental procedure}

Polyethylene terephthalate (PET) and aluminum alloy (A5052) were used as joint materials. Size of specimen was $10 \times 20 \mathrm{~mm}$ with thickness of $0.5 \mathrm{~mm}$ for the both materials. Table 1 shows mechanical and physical properties of the materials. Surfaces of the specimens were cleaned by using ethyl alcohol just before the joining experiment.

Spot joining between PET and A5052 was conducted by using pulse YAG laser. Figure 2 (a) shows the schematic illustration of the joining experiment. Thickness tape with thickness of $0.05 \mathrm{~mm}$ was placed on $\mathrm{XYZ}$ stage to
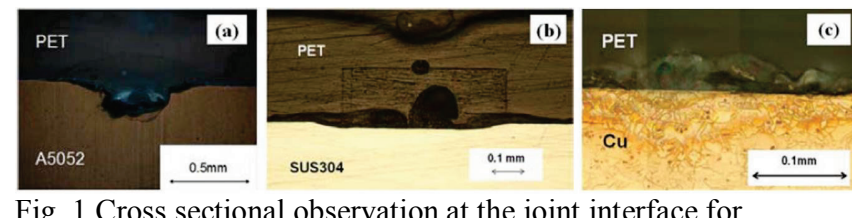

Fig. 1 Cross sectional observation at the joint interface for (a) PET/A5052, (b) PET/SUS304 and (c) PET/Cu joint [2] 
make good contact between specimens at the joint area. A5052 plate was placed on the thickness tape, and then PET plate was set on the A5052 plate. Specimens were fixed by using a fixing plate. Laser was irradiated to A5052 plate surface through PET at the focusing position with spot diameter of $0.2 \mathrm{~mm}$ approximately. Heat input changed by applying different crest value in voltage for laser pumping and pulse duration to find out weldable conditions.

Tensile shear test was performed to evaluate the joining strength. Figure 2 (b) shows the schematic illustration of tensile shear test. Testing load was applied to a joint by displacement control with cross head speed of $0.5 \mathrm{~mm} / \mathrm{min}$.

\section{Results and discussions}

\subsection{Weldable conditions}

Table 2 shows the weldable conditions for the present PET/A5052 joint. Symbol of " $x$ " in the table indicates the non-weldable conditions due to less heat input. The values indicated in table 2 shows the heating energy for one pulse at the weldable conditions. As shown in table 2, joints were obtained in a wide range of heat input. Figure 3 shows interfaces of the joints welded with several heat inputs observed from PET side. Heat inputs of Fig.3 (a), (b) and (c) were $15.7,27.2$ and $40.6 \mathrm{~J} / \mathrm{P}$, respectively. It can be seen from Fig. 3 that bubbles were formed in PET near the interface. Size and number of the bubbles increased with increase in heat input. Katayama et al [3] and the authors [4] investigated effect of bubbles on strength of the plastic/metal joint. Formation of bubbles improved the joining strength. Molten or softened plastic was pushed to metal

Table 1 Mechanical and physical property of the materials used

\begin{tabular}{l|c|c}
\hline \hline & PET & A5052 \\
\hline \hline Young's modulus, $\mathrm{GPa}$ & 5.4 & 72 \\
\hline Density, $\mathrm{kg} / \mathrm{m}^{3}$ & 1455 & 2680 \\
\hline Glass transition temperature, ${ }^{\circ} \mathrm{C}$ & 80 & - \\
\hline Melting temperature, ${ }^{\circ} \mathrm{C}$ & $200-255$ & $607-649$ \\
\hline Specific heat capacity, $\mathrm{Jkg}^{-10} \mathrm{C}^{-1}$ & 1000 & 880 \\
\hline Thermal conductivity, $\mathrm{W} / \mathrm{m}^{-1}{ }^{\circ} \mathrm{C}^{-1}$ & 0.24 & 138 \\
\hline \hline
\end{tabular}

Table 2 Weldable conditions for PET/A5052 joint.

\begin{tabular}{c|c|c}
\hline \hline \multirow{2}{*}{ Crest value [V] } & \multicolumn{2}{|c}{ Pulse duration [ms] } \\
\cline { 2 - 3 } & 10 & 20 \\
\hline \hline 50 & $\times$ & $\times$ \\
\hline 100 & $\times$ & 7.9 \\
\hline 150 & 9.6 & 16.1 \\
\hline 200 & 16.8 & 29.1 \\
\hline 250 & 24.3 & 41.2 \\
\hline 300 & 33.1 & 55.9 \\
\hline \hline
\end{tabular}

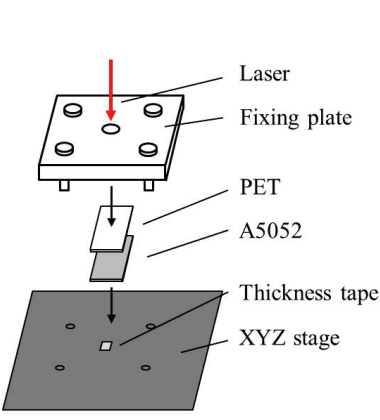

(a)Joining experiment

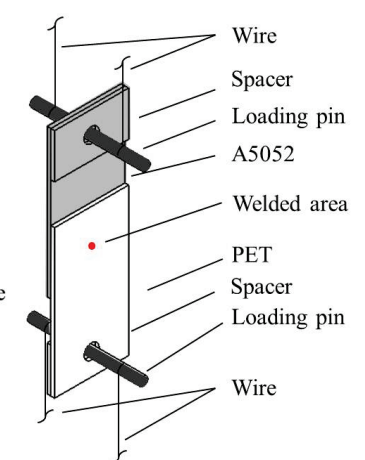

(b)Tensile shear test
Fig.2 Schematic illustration of the experiments. surface tightly with pushing force induced by high pressure inside the bubbles. However, large number and size of the bubbles formed with higher heat input decreased the strength because those played as defects.

\subsection{Evaluation of tensile shear strength of the joint}

Tensile shear test was conducted to evaluate the strength of the joint. Figure 4 shows the relationship between heat input and tensile shear failure load of the joints. Tensile shear failure load increased with increase in heat input except the joint welded with the highest heat input. Apparent strength of a joint was calculated by dividing tensile failure load by the welded area measured by observation of the interface. Figure 5 shows the relationship between heat input and the welded area. As shown in the figure, the welded area increased with increase in heat input. Figure 6 shows the relationship between heat input and the tensile shear strength. If the joining strength is only depending on bonding force at the interface, the strength should be constant regardless of welding conditions. However, as shown in Fig.6, joint strength increased with increase in the heat input until a certain value of heat input, i.e. around $25 \mathrm{~J} / \mathrm{P}$, and then varied in higher heat input region. At the maximum heat input condition, i.e. 55.9J/P, degradation of the strength was observed.
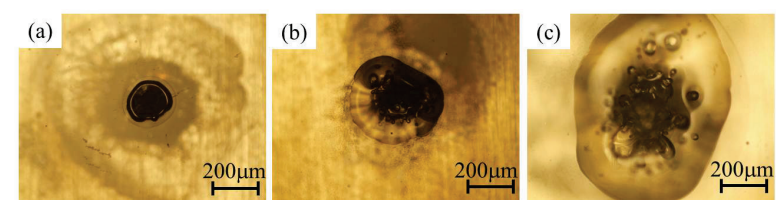

Fig. 3 Observation of the interface for joints welded with heat input of (a) 15.7, (b) 27.2 and (c) $40.6 \mathrm{~J} / \mathrm{P}$.

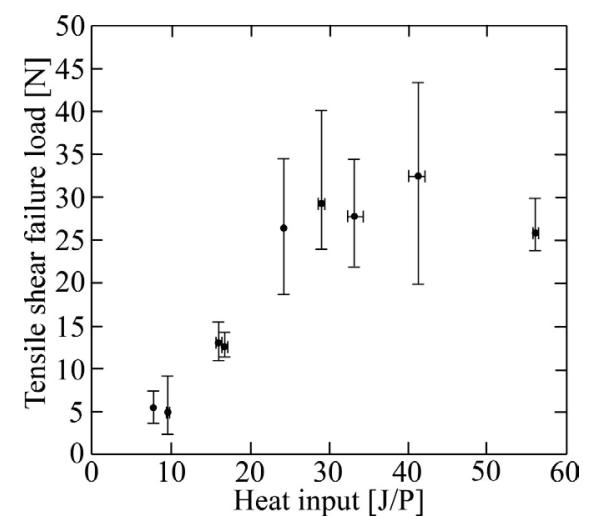

Fig. 4 Relationship between heat input and tensile shear failure load.

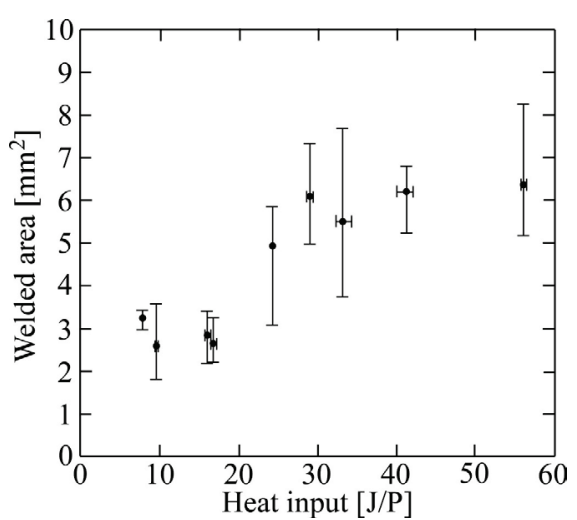

Fig. 5 Relationship between heat input and welded area. 


\subsection{Cross sectional observation}

Figure 7 shows cross sectional observation of joints welded with several heat inputs. Heat inputs in Fig.7 (a), (b), (c) and (d) were $10.4,32.4,36.8$ and $55.4 \mathrm{~J} / \mathrm{P}$, respectively. In the all cases, molten pool was formed at the interface of A5052 and its depth increased with increase in heat input. In cases of the joint welded with lower heat input condition as shown in Fig.7 (a), molten or softened plastic flowed into the molten pool of A5052. However, in cases of the joint welded with higher heat input condition as shown in Fig.7 (d), PET was not observed in the molten pool of A5052 but vacancy was existing. As mentioned in above, joining strength decreased when a joint welded with the highest heat input condition.

It was obvious that in case of a joint welded with higher heat input, the molten pool region had less load carrying capacity, and resulted in decreasing the joining strength. In cases of joints obtained by middle value of heat input, two types of joining morphologies in the molten pool were observed as shown in Fig.7 (b) and (c). Inside of the molten pool filled with PET in Fig. 7(b) but not in (c), though heat inputs for the welding and depths of the molten pool were the similar in the both joints. It is considered that the difference in the morphology inside of the molten pool induces larger scatter in the strength for the joints welded with middle value of the heat input, i.e. a kinds of transition condition causing the different morphology.

However, those change in strength mentioned in above are strongly depending on loading condition. Figure 8 shows relationship between heat input and peel strength of the PET/A5052 joint. The peel test was carried out with cross head speed of $0.5 \mathrm{~mm} / \mathrm{min}$. According to Fig. 8 , the peel strength does not increase with increase in heat input in the lower heat input region. It can be assumed that the

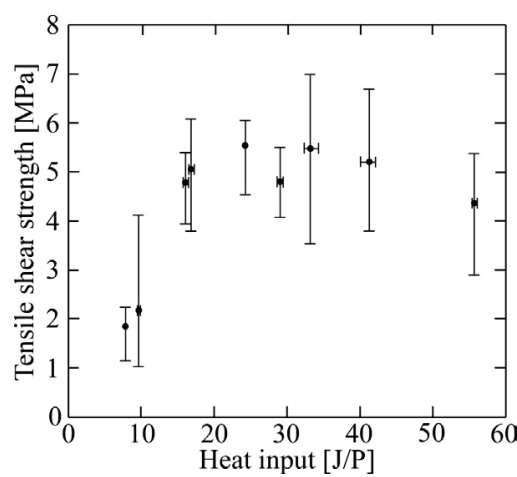

Fig. 6 Relationship between heat input and tensile shear strength.
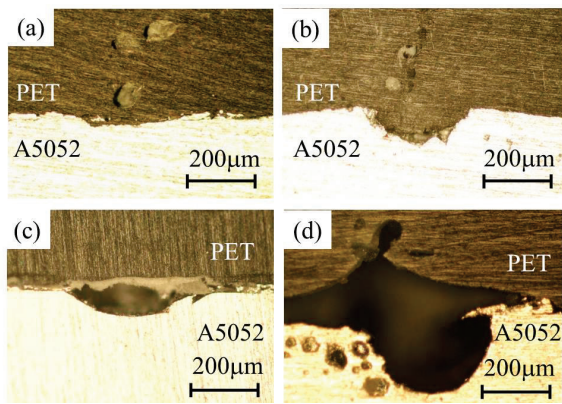

Fig. 7 Cross sectional observation at the joint interface welded with heat input of (a) 10.4, (b) 32.4, (c) 36.8 and (d) $55.4 \mathrm{~J} / \mathrm{P}$. bonding strength of the interface could be the same regardless of the heat input. The increase in tensile shear strength apparently observed in lower heat input region in Fig.6 is considerably including the effect of loading mode.

Figure 9 shows the relationship between molten pool depth and tensile shear strength. It can be seen from the figure that tensile shear strength increased with increase in the molten pool depth below $0.1 \mathrm{~mm}$ where heat input was around $25 \mathrm{~J} / \mathrm{P}$. As mentioned in above, in this lower heat input region, PET flowed into the molten pool of A5052. It can be assumed that the bonding condition inside the molten pool is the same for all joints welded with lower heat input conditions.

An increase in joining strength under tensile shear load observed in the joints welded with lower heat input conditions resulted in the joining morphology as shown in Fig7(a) is analytically investigated in the next section.

\subsection{Effect of molten pool shape}

When tensile shear loading is applied to a spot-welded lap joint, the mix mode state between Mode I (tension) and Mode II (shear) occurs at the interface, therefore, it is difficult to evaluate interfacial strength [5]. One of the general ways for the evaluation is using fracture mechanics parameters. Stress intensity factor for the interface of similar materials spot-welded lap joint under tensile shear loading is shown in the reference [6]. Watanabe et al. reported fracture mechanics analysis on cross tension test of a spotwelded lap joint by using $J$-integral [7]. In addition, in case of dissimilar materials joint, evaluation of interfacial strength is more complex due to stress discontinuity at the interface and stress singularity around an edge of interface [8]. Thus, it can be said that mechanics of interface for dissimilar materials joint has not been completely revealed yet.

In this study, three dimensional finite element analysis

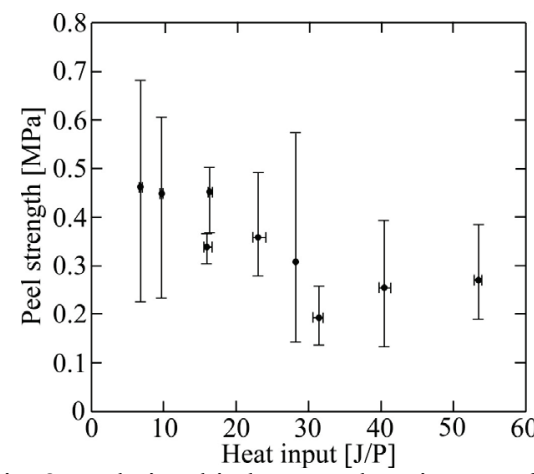

Fig. 8 Relationship between heat input and peel strength.

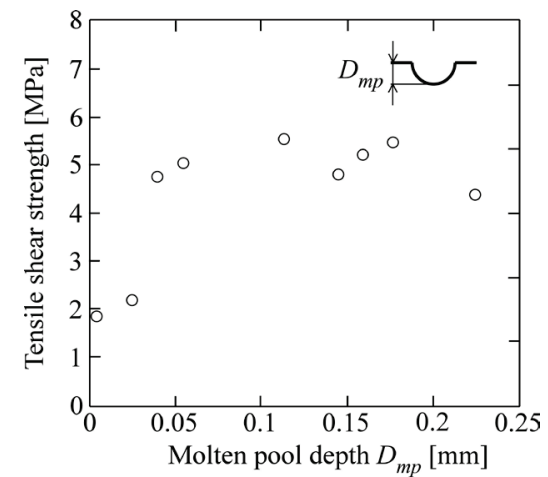

Fig. 9 Relationship between molten pool depth and tensile shear strength. 
was conducted by using a commercial FEM analysis software, ANSYS 14.0 to investigate effect of molten pool shape on tensile shear strength of PET/A5052 joint which has a molten pool filled with PET in the A5052 side. In the present model, number of nodes and elements were 27934 and 16938, respectively. The dimension and boundary condition followed the experimental condition. Tensile shear load of $0.1 \mathrm{~N}$ was applied to the model. In the model, molten pool shape was assumed as a semi-ellipsoid. In the FEM calculation, various molten pool radius and depth were introduced into the model to study those effects. As mentioned in above, mix mode condition between Mode I and Mode II occurred at the interface of a joint under tensile shear loading. The specimen is deformed to the delamination at the interface. The delamination force occurred was calculated from the displacement of a spring in the present analysis. Stiffness of the interface was unknown, but a spring constant of $5 \mathrm{~N} / \mathrm{mm}$ was assumed and introduced at the interface to estimate the interfacial strength as a spring force.

Figure 10 shows the relationship between molten pool radius $r_{m p}$ and the maximum spring force obtained at the edge of the welded area (i.e. delamination force) $F_{m p}$ in the same molten pool depth of $0.25 \mathrm{~mm}$. Note that $F_{r, 0.1}$ is defined as the spring force when $r_{m p}=0.1 \mathrm{~mm}$. It can be seen from Fig. 10 that the spring force shows almost the constant value regardless of change in the molten pool radius. Therefore, it is considered that the molten pool radius has no significant effect on jointing strength. Figure 11 shows relationship between molten pool depth $D_{m p}$ and the maximum spring force (delamination force) $F_{m p}$ with the same molten pool radius of $0.25 \mathrm{~mm}$. Note that $F_{D, 0.1}$ is defined as the spring force when $D_{m p}=0.1 \mathrm{~mm}$. It can be seen from

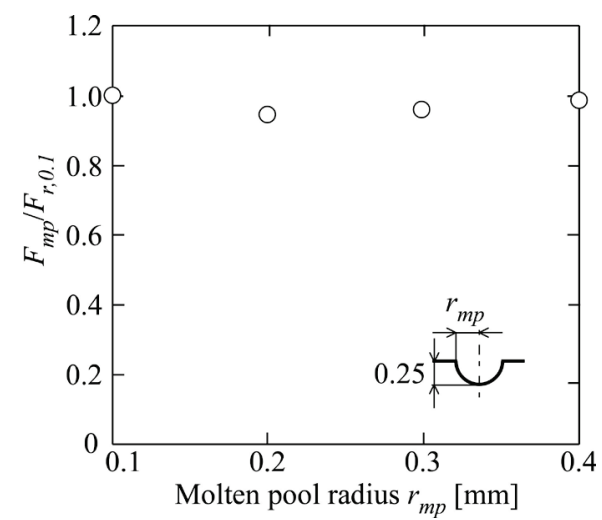

Fig. 10 Effect of molten pool radius on the spring force.

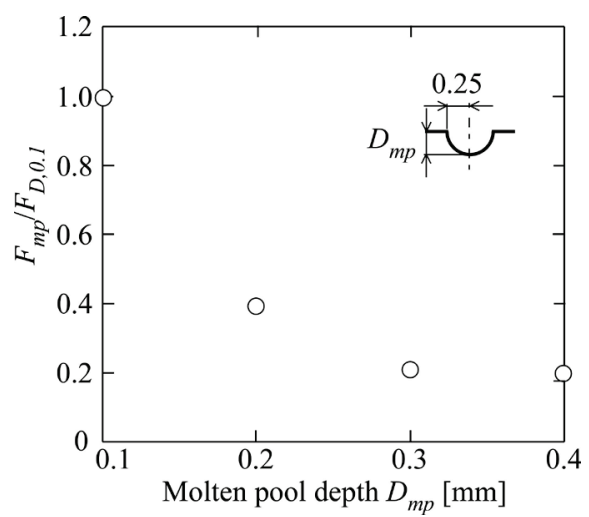

Fig. 11 Effect of molten pool depth on the spring force.
Fig.11 that the delamination force decreased with increase in molten pool depth. Therefore, it is speculated that the higher joining strength could be obtained in a joint with deeper molten pool depth. In case of deeper molten pool, displacement in Mode I direction at the joining area is suppressed and increase in joining strength apparently. This trend observed in the result of FEM analysis agrees with that observed in the result of the experiment.

According to the result of the present study, molten pool depth significantly affects tensile shear strength. Higher strength is expected in a joint with a deeper molten pool. However, fracture mode in the analysis was assumed as only delamination at the interface. Actually, several fracture modes possibly occurred. Furthermore, other factors also can affect the joining strength such as bubbles (i.e. defect) and the morphology inside the molten pool, as mentioned in above. Therefore, it is necessary to study more to find the optimized welding condition taking into account possible effects to improve the joining strength.

\section{Conclusions}

- It was possible to make a dissimilar materials laser spot joint between PET and A5052 in a wide range of heat input by pulse YAG laser.

- Tensile shear strength increased with increase in molten pool depth when the molten pool filled with melted or softened PET.

- The result of FEM analysis showed that there was not significant effect of the molten pool radius on the joining strength under tensile shear load. On the other hand, the analytical result indicated that shear tensile strength increased with increase in molten pool depth as observed in the experimental result.

\section{Acknowledgement}

The present study was supported by Grants-in-Aid for Scientific Research.

\section{References}

[1] S. Katayama and Y. Kawahito: Scripta Materialia Vol.59, (2008) pp. 1247-1250.

[2] Y. Farazila, Y. Miyashita, Wang Hua, Y.Mutoh and Y.Otsuka: Journal of Laser Micro/Nanoengineering Vol. 6, No.1, (2011) pp.69-74.

[3] M. Mauba, Y. Kawahito and S. Katayama: Journal of materials processing technology211, (2011) pp.11661174.

[4] Y. Miyashita, M. Takahashi, M. Takemi, K. Oyama, Y. Mutoh and H. Tanaka: Journal of Solid Mechanics and Materials Engineering Vol.3, No.2, (2009) pp.409-415.

[5] K. Nakasa, "Interfacial Strength Evaluation Handbook" ed. by The Society of Materials Science, Japan, (2011) pp. 1-9. (in Japanese)

[6] Y. Murakami, "Stress Intensity Factors Handbook Vol.2" ed. by The Society of Materials Science, Japan, (Prgamon Press, 1987).

[7] F. Watanabe, S. Furusako, H. Hamatani, Y. Miyazaki and T. Nose: Proceedings of Welding Mechanics Symposium 2011, (2011) p 271-278. (in Japanese)

[8] R. Yuuki, "Mechanics of Interface", Baifukan, (1993) (in Japanese).

(Received: June 11, 2012, Accepted: May 20, 2013) 